\title{
A new ophthalmosaurid ichthyosaur from the Late Jurassic of Owadów-Brzezinki Quarry, Poland
}

\author{
Daniel Tyborowski \\ Acta Palaeontologica Polonica 61 (4), 2016: 791-803 doi:http://dx.doi.org/10.4202/app.00252.2016
}

A new Late Jurassic ophthalmosaurid ichthyosaur Cryopterygius kielanae sp. nov. is described from carbonate deposits of Owadów-Brzezinki Quarry, Central Poland, corresponding in age to the Agardhfjellet Formation (Tithonian, Middle Volgian) of the Svalbard Archipelago. The new species is represented by three-dimensionally preserved bones which display several features characteristic for Cryopterygius; including appendicular skeleton, pectoral girdle and perhaps neural arches. The morphology of the Polish form is distinct enough from Cryopterygius kristiansenae from the Svalbard Archipelago to warrant erection of a new species. The size of the bones of Cryopterygius kielanae sp. nov. indicates that this species was smaller than the type species. Its diagnostic anatomical features include a humerus with prominent and well developed dorsal process located in the middle of the dorsal surface of the bone, prominent deltopectoral crest, relatively broad femur and absence of the wide groove on the quadrate articular condyle. The discovery of a new ophthalmosaurid ichthyosaur of the genus Cryopterygius in Poland suggests that the Owadów-Brzezinki area was a transition zone between the tropical Tethys Ocean and the Arctic basin during the Late Jurassic.

Key words: Ichthyosauria, Ophthalmosauridae, Late Jurassic, Poland, Owadów-Brzezinki Quarry.

Daniel Tyborowski [paleodanieltyborowski@gmail.com], Museum and Institute of Zoology, Polish Academy of Sciences, ul. Wilcza 64, 00-679 Warszawa, Poland.

This is an open-access article distributed under the terms of the Creative Commons Attribution License (for details please see creativecommons.org), which permits unrestricted use, distribution, and reproduction in any medium, provided the original author and source are credited. 
FoF Full text $(1,064.1 \mathrm{kB})$ 